BMJ Open

Ophthalmology

\title{
Human coronaviruses: ophthalmic manifestations
}

\author{
Mohd-Asyraaf Abdul-Kadir (D) , Lik Thai Lim (D)
}

To cite: Abdul-Kadir M-A, Lim LT. Human coronaviruses: ophthalmic manifestations. BMJ Open Ophthalmology 2020;5:e000630. doi:10.1136/ bmjophth-2020-000630

Received 24 September 2020 Revised 17 October 2020 Accepted 25 October 2020
Check for updates

(c) Author(s) (or their employer(s)) 2020. Re-use permitted under CC BY-NC. No commercial re-use. See rights and permissions. Published by BMJ.

Ophthalmology Department, Universiti Malaysia Sarawak (UNIMAS), Kota Samarahan, Sarawak, Malaysia

Correspondence to Professor Dr Lik Thai Lim; Itlim@unimas.my

\section{ABSTRACT}

The 2019 novel coronavirus which causes severe acute respiratory syndrome (SARS) known as SARS-CoV-2 still remains as a global pandemic since its discovery and continues to spread across the world, given how highly contagious the virus is. We reviewed various articles that explore eye involvement in COVID-19 and other human coronaviruses, its human manifestations in comparison to animal studies and potential mechanism of viral entry into the eye surface. Evidence of animal studies depicted various complications of coronaviruses infection into the eyes, in both anterior and posterior segments of the eye. Conjunctival inflammation remains uncommon in association with COVID-19, with other ophthalmic findings. The risk of transmission via the ocular surface remains likely low, though it is inarguably present based on preliminary finding of viral load in ocular samples and expression of ACE2 on the ocular surface. Testing the tears sample for diagnosing SARS-CoV-2 was unreliable due to limitations of the testing kits and conflicting evidence of the viral titre in the ocular samples. Further larger, more precise and specific studies are required to allow us to better understand the pattern of virulence underlying the associations of SARS-CoV-2 in the eye despite its rare occurrence. This review article aims to enhance better awareness among clinicians regarding ocular manifestations associated with COVID-19 and necessary precautions should be implemented to minimise the risk of person-to-person especially in the nosocomial setting.

\section{INTRODUCTION}

When the novel coronavirus $(\mathrm{CoV})$ which causes severe acute respiratory syndrome (SARS), namely SARS-CoV-2 or infamously known as COVID-19 was first recognised and reported since December 2019 in Wuhan, China, many of us understood that it is another type of severe airway disease. As time progresses, unfortunately COVID-19 had evolved into a global pandemic affecting the health of millions of people across the globe with increasing mortality as well. The virus has been associated with stroke, cardiovascular pathologies, neurological manifestations, dermatological signs as well as ocular pathologies. This review article aims to look into the ocular manifestations that have been reported to be associated with COVID-19 particularly, to enhance awareness among our colleagues of such ocular associations which can be an early sign of COVID-19 manifestation.

\section{Human coronaviruses: history}

The earliest discovery of human coronavirus $(\mathrm{HCoV})$ was reported in 1965 in patients with a common cold which was named as B814. ${ }^{1}$ Although most coronaviruses infections in human are associated with mild clinical symptoms, the notably pathogenic strains are SARS-CoV, Middle East respiratory syndrome Coronavirus (MERS-CoV) and the new SARS-CoV-2. ${ }^{2}$

The novel betacoronavirus, SARS-CoV was responsible for the first pandemic of the $21^{\text {st }}$ century between November 2002 and August 2003 that resulted in 8098 cases with fatality rate of $9.6 \%$ to $11 \%$ according to WHO. ${ }^{3}{ }^{4}$ Two human CoVs were identified before SARS-CoV, HCoV-229E and HCoVOC43. ${ }^{5}$ Following the SARS outbreak, two more strains of human coronaviruses were found, HCoV-NL63 and HCoV-HKU1. ${ }^{78}$ In 2012, MERS-CoV was first detected from a man who died from severe pneumonia and secondary renal failure in Saudi Arabia. The virus is responsible for the ongoing epidemic of respiratory disease in Middle East Region and the deadly outbreak in South Korea. ${ }^{9-11}$

On $7^{\text {th }}$ January 2020, WHO announced the new betacoronavirus following the mysterious clusters of infectious respiratory disease in Wuhan, China. ${ }^{12}$ Although the virus was named SARS-CoV-2, it was not the descendent from SARS-CoV. ${ }^{13}$ Full genome sequencing of SARS-CoV-2 from five patients at an early stage of the pandemic had shown $79.6 \%$ similarity to SARS-CoV and $50 \%$ to MERS-CoV. ${ }^{14}$ Furthermore, SARS-CoV-2 shares $96.2 \%$ of nucleotide identity with the closest bat coronavirus, which confirmed its zoonotic origin. ${ }^{15}$ As of $15^{\text {th }}$ October 2020, there have been around 37.1 million cases of SARS-CoV-2 globally with a mortality rate of almost 3\%; 1070355 deaths had been reported to $\mathrm{WHO}^{16}$ 
Human coronaviruses: transmission via ocular surface?

The emerging of human coronaviruses is likely due to its molecular diversity and its predisposition to evolve and adapt to new hosts. These are attributed to their high frequency of RNA recombination and mutation and the large genomes for RNA virus that increased the likelihood for intraspecies variability and interspecies 'host jump' under the right conditions. ${ }^{1718}$ It is postulated that both SARS-CoV and MERS-CoV were originated from bats and then 'jumped' into intermediate mammalian hosts; the Himalayan palm civet for the former and the dromedary camel for the latter before they cross species barriers to infect humans. ${ }^{19} 20$

Routes of transmission of the highly contagious SARS-CoV-2 and SARS-CoV have been mostly described via respiratory droplets on exposed mucous membrane and contact with infected persons. ${ }^{21} 22$

Following the anecdotal report of a Chinese respiratory expert on pneumonia who had contracted SARS-CoV-2 via his unprotected eyes after visiting the Wuhan Fever Clinic, health personnel were encouraged to don eye protective gears when encountering patients with COVID-19 or highly suspected patients. ${ }^{23}$ A group of authors however countered his claim as his conjunctivitis had only occurred few hours before the pneumonia and it was likely that the conjunctivitis was a coincidental finding as SARS-CoV-2 manifesting systemically into pneumonia. ${ }^{24}$ Whether this could potentiate the notion that SARS-CoV-2 can be spread via unprotected eyes is worth exploring.

\section{Human coronaviruses: potential eye complications based on} animal studies

Ocular involvement in coronaviruses infection had been widely documented in various animal studies. ${ }^{25}$ Feline coronavirus (FCoV), an alphacoronavirus for example, can cause the highly fatal feline infectious peritonitis (FIP) in 5\% of infected cats. ${ }^{26}$ Monocytes and macrophages were targeted by both biotypes of FCoV, FECV (feline enteric CoV) and FIPV (feline infectious peritonitis virus). Ocular complications secondary to FIP are conjunctivitis, pyogranulomatous anterior uveitis, choroiditis with retinal detachment and retinal vasculitis. ${ }^{27}$ The underlying mechanism of these unfortunate sequelae is likely due to the recruitment of immune cells into these tissues via the disrupted endothelial barrier dysfunction from infected monocytes and macrophages. $^{2528}$

A multitude of retinal complications secondary to coronavirus was identified in a rodent study. Retinal vasculitis and retinal degeneration were observed in a biphasic manner in genetically susceptible rodents infected by the murine coronavirus, a mouse hepatitis virus, MHV (JHM Strain). ${ }^{29}$ In a follow-up study, the authors concluded that the retinal inflammation was associated with viralinduced retinal apoptosis and another study claimed that autoimmunity could play a role in the retinal degeneration as production of autoantibodies against retina and retinal pigment epithelium that led to the gradual loss of photoreceptors and ganglion cells. ${ }^{30}{ }^{31}$ Another neurotropic strain of MHV, A59 is capable of inducing marked axonal loss and inflammatory changes including meningitis, focal encephalitis and notably optic neuritis as early as 3 days in infected mice. ${ }^{32}$

\section{Human coronaviruses: ocular manifestations}

The fourth HCoV, HCoV-NL63 was first successfully isolated from a child who had suffered from bronchiolitis and conjunctivitis. ${ }^{8}$ Conjunctivitis was reported in three patients with $\mathrm{HCoV}-\mathrm{NL} 63$ infection in a retrospective study in France. ${ }^{33}$ However, there was no scientific research at this stage that could elucidate the eye involvement in this coronavirus infection.

The impact of human coronavirus in ophthalmology has been actively investigated since the outbreak of SARS-CoV. A case series in 2003 had studied potential of testing assorted body secretions as an adjunct tool for diagnosing SARS including tears sample in a group of patients with suspicions of SARS. Tears samples from three probable SARS patients yielded positive RNA for the virus which were obtained in the early course of the disease. Interestingly, one of the patients was diagnosed with SARS-CoV based on the only positive finding in her tears sample since the respiratory swab was not sent and the stool samples were negative for SARS-CoV. The authors commented the possibility of contamination of the sample from the upper respiratory tract was plausible that could affect the outcome of the test. This study suggested eyes could play a role in early detection of SARS infection and increased awareness that the viral transmission could occur with reusable ophthalmic equipment when in contact with patient's tears thus stringent precautions need to be implemented. ${ }^{34}$

However, similar finding was not replicated in another interventional case study in Hong Kong. Tears collection and conjunctival scraping were performed along with another standard routine sampling on 20 patients; 17 patients with confirmed SARS-CoV and 3 patients suspicious for the infection. None of the samples produced positive result on either tears or conjunctival specimen. However, five of the patients yielded positive SARS-CoV RNA in both their nasopharyngeal and stool samples. These negative findings from their ocular samples could be attributed to false negatives due to lack of sensitivity of the testing RT-PCR kit, a single sample collection could miss the limited window period of viral shedding or possibly that SARS-CoV RNA did not even present in ocular tissue. Thus, the authors recommended that ocular sampling to confirm or exclude SARS-CoV infection was not reliable. ${ }^{35}$

It has been speculated that the presence of SARS-CoV RNA in tears in older studies was either due to the ocular surface being the direct site of virus replication from the infectious droplets or the migration of the virus into the eye via the nasolacrimal duct from the upper respiratory 
infected site or haematogenous spread from the lacrimal gland. ${ }^{25} 36$

Meanwhile, MERS-CoV titre was detected in five camels of their nasal and conjunctival tissue out of 76 dromedary camels in Oman. ${ }^{37}$ Despite these findings, no definitive reports of symptomatic ocular involvement in SARS-CoV and MERS-CoV infections had been published so far. ${ }^{38} 39$

Conjunctivitis associated with SARS-CoV-2 infection is not widely reported, even in an extensive retrospective data that involved 30 provinces in China, only $0.8 \%$ of the 1099 patients with established SARS-CoV-2 infection reported conjunctival congestion and none of them presented with conjunctivitis as their primary symptom. ${ }^{40}$ Ocular involvement was also not documented among 48 patients with SARS-CoV-2 in Thailand even after eye examinations in suspected cases of conjunctivitis. ${ }^{41}$ Conjunctivitis could be under-reported given the nature of the disease, which is presumably self-limiting and rarely threatening the vision. ${ }^{42}$

However, a cross-sectional study in Wuhan involving 535 patients confirmed that 4 patients presented with conjunctival congestion as their primary symptom and 27 patients in total with ocular involvement. Other additional symptoms were ocular secretion and pain, photophobia, dry eye and epiphora. The authors discovered some of these patients had underlying chronic eye diseases that includes conjunctivitis, keratitis and xerophthalmia. $^{43}$

In Argentina, a case of a unilateral conjunctivitis with oedematous eyelid in a young man had preceded the onset of fever, cough and severe shortness of breath and RT-PCR from his nasopharyngeal swab yielded positive result for SARS-CoV-2. ${ }^{44}$ A case of keratoconjunctivitis with photophobia was reported in a returning traveller from Philippines which was her primary presenting issue besides mild respiratory symptoms. Interestingly, her corneal findings include pseudodendrite, subepithelial infiltrates and multiple epithelial defects. A retrospective SARS-CoV-2 RNA PCR was done on her initial eye swab which revealed a weak positive result for the virus. ${ }^{45}$

Conjunctival involvement was identified as a late complication from SARS-CoV-2 infection as per a case report in Shenzhen, China. A man with positive SARS-CoV-2 on nasopharyngeal swab developed bilateral conjunctivitis on day 13 after his systemic symptoms manifested. This was in concordance with his positive conjunctival swabs for SARS-CoV-2 and repeated samples showed decreasing viral titre with negative result 6 days later. ${ }^{46}$ In France, a bilateral haemorrhagic conjunctivitis had been reported in an elderly male patient after nearly 2 weeks being treated in the intensive care unit for ventilator support. His other clinical signs include tarsal pseudomembranous and superficial punctate keratitis. Despite these findings, SARS-CoV-2 RNA was not detected in his conjunctival scrapings. ${ }^{47}$

Besides, a case study from Italy that described the first confirmed case of SARS-CoV-2 in the country had shown downtrending of the virus titres in the ocular secretions which had been positive for up to 21 days since the onset of her systemic and ocular symptoms. This was only a few days after the virus was undetectable in nasal swabs thus suggestive that the viral replication could be sustained in the conjunctiva. Her initial presenting symptoms were dry cough, sore throat, coryza and bilateral conjunctivitis. ${ }^{48}$ These studies could potentially shed some light into the pattern of viral shedding of SARS-CoV-2 which might be different from SARS-CoV and MERS-CoV.

A case series of 30 COVID-19 patients from Hangzhou, China, demonstrated positive SARS-CoV-2 RNA in two samples of the conjunctival swabs of the only patient who had conjunctivitis that were collected within 2 to 3 days apart while the rest of the samples from the other 29 patients without ocular involvement remained negative. ${ }^{49}$ There is another case series of larger number of COVID-19 patients with ocular involvement in association with SARS-CoV-2 infection with 12 out of 38 patients were affected in total. Common presentations were chemosis, epiphora, ocular secretions and only minor reports of conjunctival hyperaemia. Nonetheless, only two patients who demonstrated RNA of SARS-CoV-2 in their conjunctival samples. The study concluded that ocular complication from SARS-CoV-2 is likely to occur in more severe COVID-19. ${ }^{50}$

On the contrary, not all patients with SARS-CoV-2 and conjunctival inflammation will produce measurable viral load in the conjunctival or tears swabs. Singaporean researchers investigated into the potential for SARS-CoV-2 transmission via ocular tissue or fluid provided the similar resemblance of the novel coronavirus with the SARS-CoV. All 17 patients were diagnosed with SARS-CoV-2 and none of them had any ocular symptoms before the study. Tears of these 17 patients were collected multiple times within 3 to 20 days of admission and even though one patient had conjunctivitis during his early admission, none of those samples produced positive results in comparison to their nasopharyngeal swabs' findings. ${ }^{51}$

Furthermore, an unpublished article of a retrospective case study in China revealed one positive and two nearpositive conjunctival swabs with SARS-CoV-2 on RT-PCR but these patients did not develop any signs or symptoms of conjunctival inflammation. One of the patients initially presented with conjunctivitis and her conjunctival swab on presentation was negative for SARS-CoV-2. Eventually, she was diagnosed with SARS-CoV-2 and she was an anaesthetist who did not wear a protective eyewear while intubating a patient. ${ }^{52}$

In another cross-sectional study that included 72 SARS-CoV-2 patients, only two patients developed conjunctivitis and only one conjunctival swab from them that produced positive result of SARS-CoV-2 on RT-PCR. The patient was a nurse and despite wearing N95 mask while working in an emergency department, she may have potentially touched her eyelids, dislocating her eye goggles. ${ }^{53}$ The authors highlighted the potential risk for healthcare workers to contract SARS-CoV-2 via exposure 
Table 1 The incidence of ocular involvement with COVID-19 and prevalence of SARS-CoV-2 RNA in conjunctival swab in SARS-CoV-2 patients with and without conjunctival involvement.

\begin{tabular}{|c|c|c|c|c|c|}
\hline Authors (reference) & Location & $\begin{array}{l}\text { Number of patients } \\
\text { with COVID-19, } N\end{array}$ & $\begin{array}{l}\text { Number of patients } \\
\text { with ocular } \\
\text { involvement, } N\end{array}$ & $\begin{array}{l}\text { Number of patients } \\
\text { with positive SARS- } \\
\text { CoV-2 RNA RT-PCR } \\
\text { conjunctival swab } \\
\text { (with conjunctival } \\
\text { inflammation), } n\end{array}$ & $\begin{array}{l}\text { Number of patients } \\
\text { with positive SARS- } \\
\text { CoV-2 RNA RT-PCR } \\
\text { conjunctival } \\
\text { swab (without } \\
\text { conjunctival } \\
\text { inflammation), } n\end{array}$ \\
\hline Guan et $a l^{40}$ & Multiple cities, China & 1099 & 9 & Test not done & Test not done \\
\hline Chen et $a /^{43}$ & Wuhan, China & 535 & 27 & Test not done & Test not done \\
\hline Xia et $a l^{49}$ & Hangzhou, China & 30 & 1 & 1 & 0 \\
\hline Wu et $a l^{50}$ & Hubei, China & 38 & 12 & 2 & 0 \\
\hline Seah et $a l^{51}$ & Singapore & 17 & 1 & 0 & 0 \\
\hline Zhou et $\left.a\right|^{52}$ & Wuhan, China & 67 & 1 & 0 & 3 \\
\hline Zhang et $a l^{53}$ & Wuhan, China & 72 & 2 & 1 & 0 \\
\hline
\end{tabular}

CoV, coronavirus; SARS, severe acute respiratory syndrome.

through unprotected eyes as observed in these two studies. $^{53}$

According to these studies, the transmission of SARS-CoV-2 via the ocular surface is low, given the extremely low incidence of conjunctivitis among SARS-CoV-2 patients, considering the limitations of these studies. It is argued that the presence of the viral RNA in conjunctival secretions and tears in conjunctivitis did not play a significant role in determining that the virus can replicate on the ocular surface. It was likely that the viraemia secondary to SARS-CoV-2 that has led to the viral exudation in conjunctivitis. Some of the authors agreed that limited samples collection and the smaller sample size contributed to the lower prevalence of the viral RNA detection in the sample. ${ }^{49}{ }_{51}$ The accuracy of the testing method was questioned given the evidence of negative result in patients with conjunctivitis associated with SARS-CoV-2 and patients without conjunctivitis who yielded positive results. ${ }^{55}$ Table 1 depicts the comparison among studies that looked into the presence of the viral RNA in conjunctival swabs and their outcome.

Evidence of posterior eye involvement in SARS-CoV-2 infection were demonstrated in 12 patients with interesting optical coherence tomography (OCT) findings of hyper-reflective lesions within the retinal layers namely the inner plexiform and ganglion layers. However, the OCT angiography and analysis of the ganglional cells of these lesions were normal. Other additional findings were cotton wool spots and micro-haemorrhages along the retinal arcade in four patients which could suggest underlying microvascular disease. Nevertheless, all patients did not demonstrate any abnormalities in their visual acuity, pupillary reflex or evidence of intraocular inflammation. ${ }^{56}$ Another supplementary evidence to support retinal involvement in SARS-CoV-2 infection is based on a postmortem study whereby three eyes from 14 patients with SARS-CoV-2 had yielded the viral RNA analysed from their retinal biopsies. ${ }^{57}$ Table 2 illustrates the comparison between SARS-CoV-2, MERS-CoV and
SARS-CoV and the corresponding ophthalmic manifestations. $416254244-5055-60$

\section{Human coronaviruses: ocular tropism in COVID-19}

The mechanism of infectivity of SARS-CoV-2 in ocular tissue is still unknown. ${ }^{25}{ }^{61}$ In general, respiratory pathogens can manifest their ocular complications due to the anatomical conduit between the eyes and respiratory tissues, ${ }^{5462} 63$ the immunological interdependence of ocular and respiratory tissues ${ }^{64}$ and the distributions of the cellular receptors in these systems that contributes to the tropism of respiratory viruses. ${ }^{38}$

Structural analysis revealed that SARS-CoV-2 targets the ACE2, like SARS-CoV to infect host cells with slight variation in the amino acid sequence of the viral spike protein. ${ }^{1465-67}$ Cellular entry for SARS-CoV-2 is mediated by the attachment of the viral Spike (S) protein to ACE2 and further priming of $\mathrm{S}$ protein by the host cellular transmembrane protease, serine 2 (TMPRSS2) to promote viral uptake and membrane fusion. ${ }^{68} 69$ Ex-vivo studies have established that SARS-CoV-2 displayed tropism in the conjunctival epithelium, besides the conducting airways. ${ }^{70}$ Cytopathic effect exerted by SARS-CoV-2 was noted to be different than MERS-CoV and SARS-CoV; early structural changes were observed after SARS-CoV-2 inoculation especially in human airway epithelial cells at 96 hours with apparent lack of cilium beating. ${ }^{71}$

Mapping the distribution of ACE2 in human body, primarily the eye may potentially assist in studying the possible ocular complications from SARS-CoV-2. ACE2, a homologue of angiotensin-converting enzyme (ACE) plays a negative regulatory role in the renin-angiotensin system (RAS). Its functions extend beyond regulating blood pressure as it modulates inflammatory and fibrotic processes in specific tissues. ${ }^{72}$ Human intraocular RAS has been discovered and ACE2 was notably expressed in structures that regulate the aqueous humour dynamic which has been studied for a potential novel therapy for ocular diseases like glaucoma. ${ }^{73-75}$ ACE2 gene has been 


\begin{tabular}{lccll}
\hline Table 2 & Comparison between SARS-CoV-2 and other human coronaviruses (HCoV) & \\
\hline HCoV & Global mortality rate & Genomic size & Target host receptor & Known ocular manifestations \\
\hline SARS-CoV & $9.6 \%$ to $11 \%$ & $27.9 \mathrm{~kb}$ & ACE2 & Nil known \\
MERS-CoV & $37.1 \%$ & $30.1 \mathrm{~kb}$ & DPP4 & Nil known \\
SARS-CoV-2 & $2.9 \%$ & ACE2 & Conjunctival hyperaemia chemosis and \\
& & secretions \\
& & Epiphora \\
& & Eyelid oedema \\
& & Tarsal pseudomembranous \\
& & Eye discomfort \\
& & Follicular and haemorrhagic conjunctivitis \\
& & Photophobia \\
& & Superficial punctate keratitis \\
& & Corneal epithelial defect \\
& & Subepithelial infiltrates \\
& & Pseudodendrite \\
& & Dry eyes \\
& & Asymptomatic retinal lesions \\
& & Cotton wool spots \\
& & Retinal microhaemorrhages
\end{tabular}

CoV, coronavirus; MERS, Middle East respiratory syndrome; SARS, severe acute respiratory syndrome.

documented in a rodent retina, particularly in the inner nuclear layer and photoreceptors ${ }^{76}$ and ACE2 activity was established in the ciliary and vitreous bodies from a porcine study and both activities were remarkably at the same level. ${ }^{77}$ Besides, ACE2 was found to exert its anti-inflammatory effect on human retinal pigment epithelium according to a study targeting on mechanisms of retinal inflammation. ${ }^{78}$

The preliminary evidence of expression of ACE2 in the anterior ocular surface tissue has been reported recently. A Chinese experimental study on rodents had shown higher levels of gene expressions of ACE2 and TMPRSS2 in the conjunctiva compared with the corneal and conjunctival epithelium and the lacrimal gland tissues. However, they were lower in comparison to the expression of the two genes in kidney and lung. ${ }^{79}$ An Italian study on human conjunctival specimens and donor cornea revealed expression of SARS-CoV-2 receptors on the ocular surface. The expression level of ACE2 was low but abundant in the conjunctiva and lower in the cornea while TMPRSS2 was exclusively expressed in the conjunctiva at diversified level. ${ }^{80}$ Moreover, an immunohistochemistry study on 10 human eye specimens revealed expression of ACE2 and TMPRSS2 proteins in all the ocular surface tissues. ACE2 protein is markedly expressed in most superficial cornea and conjunctival epithelium hence suggests that ocular surface is indeed susceptible for SARS-CoV-2 entry and as a potential reservoir for the virus transmission. ${ }^{81}$

Meanwhile, another study had demonstrated that the presence of pterygium might act as a predisposing factor for SARS-CoV-2 infection. Expressions of ACE2 and TMPRSS2 genes were more consistently detected in conjunctival and pterygium cells from some pterygium patients. TMPRSS2 genes were not identified in any conjunctival cells but only one out of three pterygium samples. Given that both genes are needed for viral entry, thus the conjunctiva is less likely to be targeted by SARS-CoV-2 compared with pterygium cells. In addition, the study showed that ACE2 gene was strongly expressed at a lower amount, while TMPRSS2 genes expression in mouse cornea was comparable to the lung tissue. ${ }^{82}$

On the contrary, a German study did not manage to identify any evidence of ACE2 and its corresponding co-factors in 38 conjunctival samples. This finding contradicted the previous positive findings in both human and animal studies and thus suggested that transmission of the virus via conjunctiva was deemed unlikely according to the authors. ${ }^{83}$ Possible explanation behind these incongruent findings remained unclear but other authors hypothesised that there could be differences in methodologies and techniques used in the study or the results were possibly affected by the quality of the samples. ${ }^{81}$

Nonetheless, the evidence that supports the presence of ACE2 and TMPRSS2 on ocular surface could possibly explain the underlying mechanism of conjunctivitis in SARS-CoV-2 infection. Evidence of reduced ACE2 expression has been observed in SARS-CoV infection and this is further corroborated by worsening of acute lung injury in mice that were given SARS-CoV Spike protein. ${ }^{84}$ Thus, given the anti-inflammatory role of ACE2 and its reduced expression in SARS-CoV infected mice, this could suggest the inflammatory process in the conjunctival tissues seen in conjunctivitis-related COVID-19. ${ }^{82}$

On the contrary, the rare occurrence of conjunctivitis could be due to the protective effect accorded by the immune system of the ocular surface, in particular the antimicrobial agents in the tear film such as lactoferrin. As seen in previous studies in SARS, cell surface molecules, heparan sulfate proteoglycans (HSPGs) provides early attachment sites for SARS-CoV invasion and lactoferrin was observed to bind to HSPGs thus preventing the 
preliminary interaction between SARS-CoV and the host cells. $^{85}$

\section{CONCLUSION}

The exact mechanisms of these clinical ocular findings in correlation with SARS-CoV-2 were yet to be studied. Inconsistency of incidence and prevalence, notably conjunctivitis in COVID-19 across the multiple studies could be confounded by other unobserved factors. The limited preliminary data suggest the likelihood of SARS-CoV-2 to infect via the ocular surface is low though the risk of transmission of the virus via the ocular surface is inarguably present given evidence of viral RNA presence in the tears fluid. ${ }^{51}$ This highlighted the importance of detecting early eye symptoms, particularly conjunctival inflammation in patients who are highly suspicious of being infected with SARS-CoV-2 according to their travel and contact history. Even though the viral RNA can be detected on some of the conjunctival swabs, the virus was not successfully cultured and grown. ${ }^{49}$ It is crucial to emphasise that RT-PCR of the conjunctival swab could not be implemented as a diagnostic test for SARS-CoV-2 given the variability of its results which was dependent on the methods and quality of the collected samples. It is worth to follow-up COVID-19 patients longer to further explore potential ocular manifestations as seen in animal studies. As for now, existing data showed ophthalmic manifestations in COVID-19 were non-sight threatening and involved inflammation of the conjunctiva and occasional isolated retinal findings. ${ }^{25} 56$

When an ophthalmologist, Dr Li Wenliang first alerted the new infectious respiratory disease outbreak in Wuhan, he was accused for disrupting social harmony. He later died from complication of SARS-CoV-2 which he contracted apparently from an asymptomatic patient. ${ }^{86}$ Often, ophthalmologists will be the first medical professional in diagnosing patients' systemic diseases based on their early ocular presentations or during routine ophthalmic examinations. Nevertheless, it may be more prudent for ophthalmologists to wear a protective eye shield while examining suspected patients. ${ }^{87}$ In addition, as a general precaution for safety, it is preferable for the attending clinicians involved in any aerosol producing procedures to wear appropriate personal protective equipment (PPE) in the interest and priority of health and safety especially during this COVID-19 pandemic while the number of cases continues to soar for now. ${ }^{61}$

Contributors The author, MA researched and reviewed the articles sourced from PubMed, prepared the review article and designed the tables. The co-author, LLT revised, edited the article and added references that were necessary for the article.

Funding The authors have not declared a specific grant for this research from any funding agency in the public, commercial or not-for-profit sectors.

\section{Competing interests None declared.}

Patient consent for publication Not required.

Provenance and peer review Not commissioned; internally peer reviewed.

Open access This is an open access article distributed in accordance with the Creative Commons Attribution Non Commercial (CC BY-NC 4.0) license, which permits others to distribute, remix, adapt, build upon this work non-commercially, and license their derivative works on different terms, provided the original work is properly cited, appropriate credit is given, any changes made indicated, and the use is non-commercial. See: http://creativecommons.org/licenses/by-nc/4.0/.

\section{ORCID iDs}

Mohd-Asyraaf Abdul-Kadir http://orcid.org/0000-0002-2414-8232

Lik Thai Lim http://orcid.org/0000-0002-0691-9769

\section{REFERENCES}

1 Tyrrell DA, Bynoe ML. Cultivation of a novel type of COMMON-COLD virus in organ cultures. Br Med J 1965;1:1467-70.

2 Su S, Wong G, Shi W, et al. Epidemiology, genetic recombination, and pathogenesis of coronaviruses. Trends Microbiol 2016;24:490-502.

3 Chan-Yeung M, Xu R-H. Sars: epidemiology. Respirology 2003;8:S9-14.

4 World Health Organization. Consensus document on the epidemiology of severe acute respiratory syndrome (SARS)-epidemic alert \& response, 2003. Available: https://www.who.int/csr/sars/en/ WHOconsensus.pdf?ua $=1$

5 Hamre D, Procknow JJ. A new virus isolated from the human respiratory tract. Proc Soc Exp Biol Med 1966;121:190-3.

6 Mclntosh K, Dees JH, Becker WB, et al. Recovery in tracheal organ cultures of novel viruses from patients with respiratory disease. Proc Natl Acad Sci U S A 1967;57:933-40.

7 Fouchier RAM, Hartwig NG, Bestebroer TM, et al. A previously undescribed coronavirus associated with respiratory disease in humans. Proc Natl Acad Sci U S A 2004;101:6212-6.

8 van der Hoek L, Pyrc K, Jebbink MF, et al. Identification of a new human coronavirus. Nat Med 2004;10:368-73.

9 Zaki AM, van Boheemen S, Bestebroer TM, et al. Isolation of a novel coronavirus from a man with pneumonia in Saudi Arabia. N Engl $J$ Med 2012;367:1814-20.

10 Raj VS, Osterhaus ADME, Fouchier RAM, et al. Mers: emergence of a novel human coronavirus. Curr Opin Virol 2014;5:58-62.

$11 \mathrm{Kim} \mathrm{KH}$, Tandi TE, Choi JW, et al. Middle East respiratory syndrome coronavirus (MERS-CoV) outbreak in South Korea, 2015: epidemiology, characteristics and public health implications. $J$ Hosp Infect 2017;95:207-13.

12 World Health Organization. Coronavirus, 2020. Available: https:// www.who.int/health-topics/coronavirus - tab=tab_1

13 Coronaviridae Study Group of the International Committee on Taxonomy of Viruses. The species severe acute respiratory syndrome-related coronavirus: classifying 2019-nCoV and naming it SARS-CoV-2. Nat Microbiol 2020;5:536-44.

14 Zhou P, Yang X-L, Wang X-G, et al. A pneumonia outbreak associated with a new coronavirus of probable bat origin. Nature 2020;579:270-3.

15 Ceraolo C, Giorgi FM. Genomic variance of the 2019-nCoV coronavirus. J Med Virol 2020;92:522-8.

16 World Health Organization. Coronavirus disease (COVID-19) weekly epidemiological update and weekly operational update, 2020. Available: https://www.who.int/docs/default-source/coronaviruse/ situation-reports/20201012-weekly-epi-update-9.pdf [Accessed 12 Oct 2020].

17 Woo PCY, Wang M, Lau SKP, et al. Comparative analysis of twelve genomes of three novel group $2 \mathrm{C}$ and group $2 \mathrm{D}$ coronaviruses reveals unique group and subgroup features. $J$ Virol 2007:81:1574-85.

18 Woo PCY, Lau SKP, Huang Y, et al. Coronavirus diversity, phylogeny and interspecies jumping. Exp Biol Med 2009;234:1117-27.

19 Chan JFW, Lau SKP, To KKW, et al. Middle East respiratory syndrome coronavirus: another zoonotic betacoronavirus causing SARS-like disease. Clin Microbiol Rev 2015;28:465-522.

20 Chan JF-W, To KK-W, Tse H, et al. Interspecies transmission and emergence of novel viruses: lessons from bats and birds. Trends Microbiol 2013;21:544-55.

21 Yang C, Ma QY, Zheng YH, et al. [Transmission routes of 2019-novel coronavirus (2019-nCoV)]. Zhonghua Yu Fang Yi Xue Za Zhi 2020;54:374-7.

22 Peiris JSM, Yuen KY, Osterhaus ADME, et al. The severe acute respiratory syndrome. N Engl J Med 2003;349:2431-41.

23 Sun C-B, Wang Y-Y, Liu G-H, et al. Role of the eye in transmitting human coronavirus: what we know and what we do not know. Front Public Health 2020;8:155.

24 Peng Y, Zhou Y-H. Is novel coronavirus disease (COVID-19) transmitted through conjunctiva? J Med Virol 2020. doi:10.1002/ jmv.25753. [Epub ahead of print: 16 Mar 2020]. 
25 Seah I, Agrawal R. Can the coronavirus disease 2019 (COVID-19) affect the eyes? A review of coronaviruses and ocular implications in humans and animals. Ocul Immunol Inflamm 2020;28:391-5.

26 Chang HW, Egberink HF, Rottier PJM. Sequence analysis of feline coronaviruses and the circulating virulent/avirulent theory. Emerg Infect Dis 2011;17:744-6.

27 Doherty MJ. Ocular manifestations of feline infectious peritonitis. $J$ Am Vet Med Assoc 1971;159:417-24.

28 Kipar A, May H, Menger S, et al. Morphologic features and development of granulomatous vasculitis in feline infectious peritonitis. Vet Pathol 2005;42:321-30.

29 Wang Y, Burnier M, Detrick B, et al. Genetic predisposition to coronavirus-induced retinal disease. Invest Ophthalmol Vis Sci 1996;37:250-4.

30 Wang Y, Detrick B, Yu ZX, et al. The role of apoptosis within the retina of coronavirus-infected mice. Invest Ophthalmol Vis Sci 2000;41:3011-8.

31 Hooks JJ, Percopo C, Wang Y, et al. Retina and retinal pigment epithelial cell autoantibodies are produced during murine coronavirus retinopathy. J Immunol 1993;151:3381-9.

32 Shindler KS, Kenyon LC, Dutt M, et al. Experimental optic neuritis induced by a demyelinating strain of mouse hepatitis virus. J Virol 2008;82:8882-6.

33 Vabret A, Mourez T, Dina J, et al. Human coronavirus NL63, France. Emerg Infect Dis 2005;11:1225-9.

34 Loon S-C, Teoh SCB, Oon LLE, et al. The severe acute respiratory syndrome coronavirus in tears. Br J Ophthalmol 2004;88:861-3.

35 Chan WM, Yuen KSC, Fan DSP, et al. Tears and conjunctival scrapings for coronavirus in patients with SARS. Br J Ophthalmol 2004;88:968-9.

36 Tong T, Lai TS-to, TS-t L. The severe acute respiratory syndrome coronavirus in tears. Br J Ophthalmol 2005;89:392.

37 Nowotny N, Kolodziejek J. Middle East respiratory syndrome coronavirus (MERS-CoV) in dromedary camels, Oman, 2013. Euro Surveill 2014;19:20781.

38 Belser JA, Rota PA, Tumpey TM. Ocular tropism of respiratory viruses. Microbiol Mol Biol Rev 2013;77:144-56.

39 Arabi YM, Balkhy HH, Hayden FG, et al. Middle East respiratory syndrome. N Engl J Med 2017;376:584-94.

40 Guan W-J, Ni Z-Y, Hu Y, W-j G, Z-y N, et al. Clinical characteristics of coronavirus disease 2019 in China. N Engl J Med 2020;382:1708-20.

41 Mungmungpuntipantip R, Wiwanitkit V, manifestation O. Ocular manifestation, eye protection, and COVID-19. Graefes Arch Clin Exp Ophthalmol 2020;258:1339.

42 Hu K, Patel J, Patel BC. Ophthalmic manifestations of coronavirus (COVID-19. Treasure Island (FL): StatPearls Publishing LLC, 2020.

43 Chen L, Deng C, Chen X, et al. Ocular manifestations and clinical characteristics of 535 cases of COVID-19 in Wuhan, China: a crosssectional study. Acta Ophthalmol 2020;24.

44 Daruich A, Martin D, Bremond-Gignac D. Unilateral conjunctivitis as first presentation of coronavirus disease 2019 (COVID-19): a telemedicine diagnosis. J Fr Ophtalmol 2020;43:e167-8.

45 Cheema M, Aghazadeh H, Nazarali S, et al. Keratoconjunctivitis as the initial medical presentation of the novel coronavirus disease 2019 (COVID-19). Can J Ophthalmol 2020;55:e125-9.

46 Chen L, Liu M, Zhang Z, et al. Ocular manifestations of a hospitalised patient with confirmed 2019 novel coronavirus disease. Br J Ophthalmol 2020;104:748-51.

47 Navel V, Chiambaretta F, Dutheil F. Haemorrhagic conjunctivitis with pseudomembranous related to SARS-CoV-2. Am J Ophthalmol Case Rep 2020;19:100735.

48 Colavita F, Lapa D, Carletti F, et al. SARS-CoV-2 isolation from ocular secretions of a patient with COVID-19 in Italy with prolonged viral RNA detection. Ann Intern Med 2020;173:242-3.

$49 \mathrm{Xia}$ J, Tong J, Liu M, et al. Evaluation of coronavirus in tears and conjunctival secretions of patients with SARS-CoV-2 infection. $J$ Med Virol 2020;92:589-94.

50 Wu P, Duan F, Luo C, et al. Characteristics of ocular findings of patients with coronavirus disease 2019 (COVID-19) in Hubei Province, China. JAMA Ophthalmol 2020;138:575-8.

51 Seah IYJ, Anderson DE, Kang AEZ, et al. Assessing viral shedding and infectivity of tears in coronavirus disease 2019 (COVID-19) patients. Ophthalmology 2020;127:977-9.

52 Zhou Y, Zeng Y, Tong Y, et al. Ophthalmologic evidence against the interpersonal transmission of 2019 novel coronavirus through conjunctiva. medRxiv 2020

53 Zhang X, Chen X, Chen L, et al. The evidence of SARS-CoV-2 infection on ocular surface. Ocul Surf 2020;18:360-2.

54 Qing H, Li Z, Yang Z, et al. The possibility of COVID-19 transmission from eye to nose. Acta Ophthalmol 2020;98:e388-e.
55 Casalino G, Monaco G, Di Sarro PP, et al. Coronavirus disease 2019 presenting with conjunctivitis as the first symptom. Eye 2020;34:1235-6.

56 Marinho PM, Marcos AAA, Romano AC, et al. Retinal findings in patients with COVID-19. Lancet 2020;395:1610-

57 Casagrande M, Fitzek A, Püschel K, et al. Detection of SARS-CoV-2 in human retinal biopsies of deceased COVID-19 patients. Ocul Immunol Inflamm 2020;28:721-5.

58 World Health Organization. MERS situtation update, 2020. Available: http://www.emro.who.int/pandemic-epidemic-diseases/mers-cov/ mers-situation-update-january-2020.html

59 Tang D, Comish P, Kang R. The hallmarks of COVID-19 disease. PLOS Pathog 2020;16:e1008536.

60 Chen L, Deng C, Chen X, et al. Ocular manifestations and clinical characteristics of 535 cases of COVID-19 in Wuhan, China: a crosssectional study. Acta Ophthalmol 2020. doi:10.1111/aos.14472. [Epub ahead of print: 18 May 2020].

61 Li J-PO, Lam DSC, Chen Y, et al. Novel coronavirus disease 2019 (COVID-19): the importance of recognising possible early ocular manifestation and using protective eyewear. $\mathrm{Br} \mathrm{J}$ Ophthalmol 2020;104:297-8.

62 Knop E, Knop N. Anatomy and immunology of the ocular surface. Chem Immunol Allergy 2007;92:36-49.

63 Paulsen F. Functional anatomy and immunological interactions of ocular surface and adnexa. Dev Ophthalmol 2008;41:21-35.

64 Chentoufi AA, Dasgupta G, Nesburn AB, et al. Nasolacrimal duct closure modulates ocular mucosal and systemic CD4(+) T-cell responses induced following topical ocular or intranasa immunization. Clin Vaccine Immunol 2010;17:342-53.

65 Lu R, Zhao X, Li J, et al. Genomic characterisation and epidemiology of 2019 novel coronavirus: implications for virus origins and receptor binding. Lancet 2020;395:565-74.

66 Li W, Moore MJ, Vasilieva N, et al. Angiotensin-converting enzyme 2 is a functional receptor for the SARS coronavirus. Nature 2003;426:450-4.

67 Shang J, Ye G, Shi K, et al. Structural basis of receptor recognition by SARS-CoV-2. Nature 2020;581:221-4.

68 Hoffmann M, Kleine-Weber H, Schroeder S, et al. SARS-CoV-2 cell entry depends on ACE2 and TMPRSS2 and is blocked by a clinically proven protease inhibitor. Cell 2020;181:271-80.

69 Heurich A, Hofmann-Winkler H, Gierer S, et al. Tmprss2 and ADAM17 cleave ACE2 differentially and only proteolysis by TMPRSS2 augments entry driven by the severe acute respiratory syndrome coronavirus spike protein. J Virol 2014;88:1293-307.

70 Hui KPY, Cheung M-C, Perera RAPM, et al. Tropism, replication competence, and innate immune responses of the coronavirus SARS-CoV-2 in human respiratory tract and conjunctiva: an analysis in ex-vivo and in-vitro cultures. Lancet Respir Med 2020;8:687-95.

71 Zhu N, Zhang D, Wang W, et al. A novel coronavirus from patients with pneumonia in China, 2019. N Engl J Med 2020;382:727-33.

72 Mirabito Colafella KM, Bovée DM, Danser AHJ. The reninangiotensin-aldosterone system and its therapeutic targets. Exp Eye Res 2019;186:107680.

73 Holappa M, Vapaatalo H, Vaajanen A. Many faces of reninangiotensin system - focus on eye. Open Ophthalmol J 2017;11:122-42.

74 Giese MJ, Speth RC. The ocular renin-angiotensin system: a therapeutic target for the treatment of ocular disease. Pharmacol Ther 2014;142:11-32.

75 Choudhary R, Kapoor MS, Singh A, et al. Therapeutic targets of renin-angiotensin system in ocular disorders. J Curr Ophthalmol 2017;29:7-16.

76 Tikellis $\mathrm{C}$, Johnston $\mathrm{Cl}$, Forbes $\mathrm{JM}$, et al. Identification of angiotensin converting enzyme 2 in the rodent retina. Curr Eye Res 2004;29:419-27.

77 Luhtala S, Vaajanen A, Oksala O, et al. Activities of angiotensinconverting enzymes ACE1 and ACE2 and inhibition by bioactive peptides in porcine ocular tissues. J Ocul Pharmacol Ther 2009;25:23-8.

78 Tao L, Qiu Y, Fu X, et al. Angiotensin-converting enzyme 2 activator diminazene aceturate prevents lipopolysaccharide-induced inflammation by inhibiting MAPK and NF-KB pathways in human retinal pigment epithelium. J Neuroinflammation 2016;13:35.

79 Zhang BN, Wang Q, Liu T, et al. [A special on epidemic prevention and control: analysis on expression of 2019-nCoV related ACE2 and TMPRSS2 in eye tissues]. Zhonghua Yan Ke Za Zhi 2020;56.

80 Leonardi A, Rosani U, Brun P. Ocular surface expression of SARSCoV-2 receptors. Ocul Immunol Inflamm 2020;28:735-8. 
81 Zhou L, Xu Z, Castiglione GM, et al. ACE2 and TMPRSS2 are expressed on the human ocular surface, suggesting susceptibility to SARS-CoV-2 infection. Ocul Surf 2020;18:537-44.

$82 \mathrm{Ma} \mathrm{D}$, Chen C-B, Jhanji V, et al. Expression of SARS-CoV-2 receptor ACE2 and TMPRSS2 in human primary conjunctival and pterygium cell lines and in mouse cornea. Eye 2020;34:1212-9.

83 Lange C, Wolf J, Auw-Haedrich C, et al. Expression of the COVID-19 receptor ACE2 in the human conjunctiva. J Med Virol 2020. doi:10.1002/jmv.25981. [Epub ahead of print: 06 May 2020].
84 Kuba K, Imai Y, Rao S, et al. A crucial role of angiotensin converting enzyme 2 (ACE2) in SARS coronavirus-induced lung injury. Nat Med 2005;11:875-9.

85 Lang J, Yang N, Deng J, et al. Inhibition of SARS pseudovirus cell entry by lactoferrin binding to heparan sulfate proteoglycans. PLOS One 2011;6:e23710-e.

86 Green A. Li Wenliang. Lancet 2020;395:682.

87 Lu C-W, Liu X-F, Jia Z-F. 2019-nCoV transmission through the ocular surface must not be ignored. Lancet 2020;395:e39. 